\section{Adenocarcinoma uretral}

\section{Urethral adenocarcinoma}

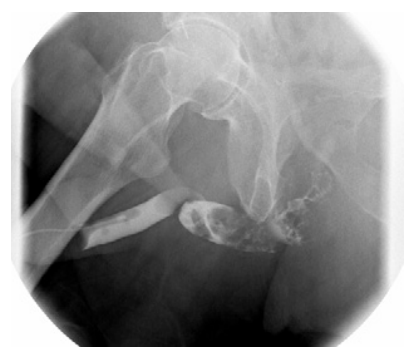

Figura 1 - Uretrografía retrograda en proyección oblicua.

H. Pastor Navarro*, M.J. Donate Moreno, J. Martinez Ruiz, P. Carrion Lopez, C. Martinez Sanchiz y J.A. Virseda Rodriguez

Servicio Urología, Complejo Hospitalario Universitario de Albacete, España

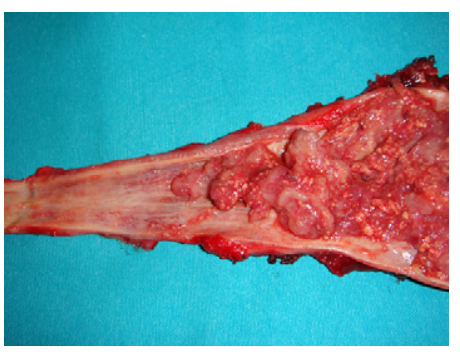

Figura 2 - Detalle del tumor en la zona distal.

*Autor para correspondencia.

Correo electrónico: hektorpn@hotmail.com (H. Pastor Navarro)

\title{
Quiste congénito gigante de próstata asociado a agenesia renal homolateral. Presentación asíntomática en adulto
}

\section{Congenital protatic cyst associated with homolateral renal agenesis. An asymptomatic case report of an adult}

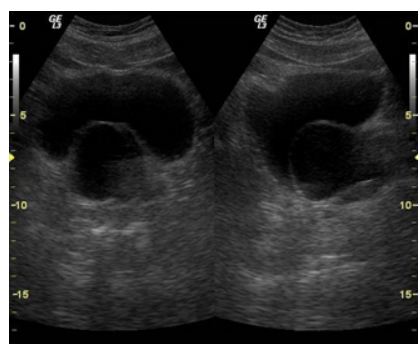

Figura 1 - Imagen ecográfica transversal y longitudinal realizada el primer día en la consulta de alta resolución. Se observa imagen redondeada anecoica con pared fina de unos $5 \mathrm{~cm}$ compatible con quiste prostático.

J. Navarro Gil*, J.A. Pérez Arbej, J.M. Sánchez Zalabardo, D. García Calero, I. Hijazo Conejos y J.G. Valdivia Uría

Servicio de Urología, Hospital Clínico Universitario «Lozano Blesa», Zaragoza, España

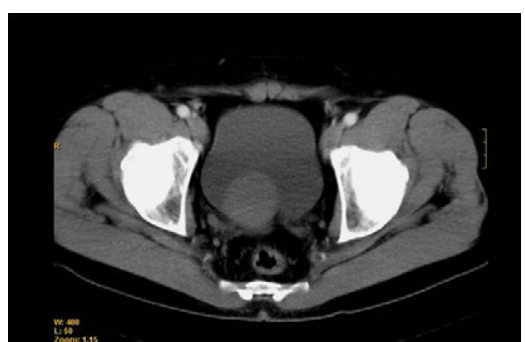

Figura 2 - Imagen ecográfica transrectal anterior y posterior al tratamiento endourológico.

\footnotetext{
*Autor para correspondencia.

Correo electrónico: telonman@hotmail.com (J. Navarro Gil)
}

doi: 10.1016/j.acuro.2010.01.010 